\title{
Maternal and fetal characteristics of premature deliveries in Western
}

\author{
Sarah Ourrad, Noria Harir ${ }^{*}$, Feriel Sellam, Soumia Zeggai \\ Laboratory of Molecular Microbiology, Proteomics and Health, Departement of Biology, Djillali Liabes University of Sidi bel \\ Abbes, Algeria
}

\begin{abstract}
We performed a retrospective descriptive analytical study over all preterm birth babies along the period of 2011-2012 at the level of neonatology department of Sidi Bel Abbes city (Western Algeria). Primigravida (OR=7, 95\% CI: 3, 16), primiparous $(\mathrm{OR}=6.23,95 \% \mathrm{CI}: 1.5,9.5)$ and mother's age $<25$ years $(\mathrm{OR}=5.8,95 \% \mathrm{CI}: 1.5,8.9)$ were the major risk factors of premature delivery. Abortion also raised the odds (OR=2.1, 95\% CI: 1.2, 2.56). Twin delivery and intra uterine growth were also marginally significantly associated with premature delivery $(\mathrm{OR}=2.15 ; \mathrm{OR}=$ respectively). Preterm babies suffered mainly from icterus and asphyxia. Prematurity is still considered as a major public health in developing countries and its causes in our studied area were multifactorial.
\end{abstract}

Key Words: Preterm birth, maternal sociodemographics characteristics, fetal characteristics, Western Algeria

\section{Introduction}

Birth of a baby less than 37 weeks of gestational age is known as preterm birth. The reduction of preterm birth is a demanding proposal since the cause, in many situations; it is hard to get hold off (1). Due to its complex nature, mechanisms underpinning preterm birth are not clearly understood. Causal factors of that include medical conditions of the mother or foetus, genetic influences, environmental exposure, infertility treatments, behavioral and socio-economic factors as well as iatrogenic prematurity (2).

The occurrence of complications, and mortality rate, were found to be higher in preterm babies. In fact preterm ones have an increased risk of death in the first year of life (infant mortality), with most of the deaths occurring in the first month of life (neonatal mortality) (3). This is often summarized by contrasting the pattern of preterm births, which comprise $6-10 \%$ of all births in Western countries, with that of preterm deaths, which comprise more than two-thirds of all perinatal deaths. Furthermore, among surviving infants, preterm birth is implicated in approximately half of all pediatric neurodevelopmental disabilities, (4-5) including cerebral palsy (6), long-term morbidity, $(7,8,4)$ and high healthcare costs $(9,10)$. Data on preterm birth rates are not routinely collected in many countries as well as in Algeria, and there were no published findings on maternal and fetal characteristics of premature deliveries in Western Algeria. Therefore, and in order to promote the primary prevention of prematurity in our region, our aim was to determine the possible risk factors which are common causes of preterm deliveries in mothers delivered at the neonatology department of obstetrics and Gynecology Specialized Hospital of Sidi Bel Abbes city (Western Algeria) as well as fetal characteristics of preterm birth babies. Information derived from the study will be used in public enlightenment campaigns on the prevention of preterm birth in Algeria.

\section{Materials and methods}

This retrospective descriptive analytical study was carried out among all those patients who delivered term and pre-term babies at the level of the Gynecology and Obstetrics wards of Sidi Bel Abbes Hospital city over period of two years (January 2011 to December 2012). We focused on patients who delivered babies at less than 37 weeks of gestation (preterm), while control were the patients who had given birth to babies of gestational age $>37$ and $<42$ weeks (term infants). A total of 600 patients' case -witnesses, became a part of this study. The information regarding the gestational history of the participants was 
collected through a pre-tested and approved questionnaire from department archives. The performa was divided into two sections. The different information aimed at assessing the socioeconomic status of the patient, diseases like: high blood pressure, diabetes, urogenital infections, anemia, parity and any previous history of preterm delivery and neonatal characteristics were also recorded.

The collected information using medical records of patients and control-groups were assessed to find out the possible risk factors leading to preterm delivery.

Data Analysis: Data were entered and analysed with Stat-view 1995. A significant level was preset at 0.05 and $95 \%$ C.I. were reported as appropriate. Logistic regression was used to investigate the association of maternal sociodemographic and fetal characteristics on premature delivery.

\section{Results}

Table 1 shows the frequency distribution of sociodemographic characteristics of the mothers. The mean age of the mothers with premature delivery was $26 \pm 6$ years, while for the control was $29 \pm 6$ years. The average number of children for both groups was 2. The median primiparous was $2 \pm 1$ for the cases and for the controls.

Premature deliveries were significantly more common $(p=0.001)$ among the mothers in the age group of more than $<25$ years old compared to mothers from other age groups. About half of the cases were primiparous mothers $(50.33 \%)$, while more than half of the control group were multiparous (67\%). 2/3 of the mothers in the cases' group were multigravida $(66 \%)$ and about $36.33 \%$ of them suffered from high blood pressure. About half of the controls were primigravida, and $41.67 \%$ of them suffered from high blood pressure.

Table 1. The frequency distribution of socio-demographic characteristics of the mothers

\begin{tabular}{|c|c|c|c|}
\hline \multicolumn{2}{|c|}{ Socio demographic characteristic } & \multirow{2}{*}{$\begin{array}{c}\text { Cases }(n=300) \\
n(\%)\end{array}$} & \multirow{2}{*}{$\begin{array}{c}\text { Controls }(\mathrm{n}=300) \\
\mathrm{n}(\%)\end{array}$} \\
\hline Age (years) & Mean s.d & & \\
\hline Parity/number of Children & Median s.d & $2 \pm 1$ & $2 \pm 1$ \\
\hline Gestity & Median s.d & $2 \pm 1$ & $2 \pm 1$ \\
\hline \multicolumn{4}{|l|}{ Age groups in years } \\
\hline$<25$ & & $189(63)$ & $92(30.67)$ \\
\hline $20-40$ & & $99(33)$ & $121(40.33)$ \\
\hline$>40$ & & $12(4)$ & $87(29)$ \\
\hline \multicolumn{4}{|l|}{ Parity: } \\
\hline 1 & & $151(50.33)$ & $124(41.33)$ \\
\hline $2-3$ & & $105(35)$ & $25(8.33)$ \\
\hline$>3$ & & $44(14.67)$ & $201(67)$ \\
\hline \multicolumn{4}{|l|}{ Gestity } \\
\hline 1 & & $198(66)$ & $145(48.33)$ \\
\hline $2-3$ & & $35(11.67)$ & $89(29.67)$ \\
\hline$>3$ & & $67(22.33)$ & $66(22)$ \\
\hline \multicolumn{4}{|l|}{ History obstetrics } \\
\hline Scarred uterus & & $53(17.68)$ & $78(26)$ \\
\hline Premature & & $46(15.33)$ & $27(9)$ \\
\hline Low Weight birth & & $113(70.63)$ & $27(16.88)$ \\
\hline Abortion & & $59(20)$ & $59(20)$ \\
\hline \multicolumn{4}{|c|}{ Diseases associated with pregnancy } \\
\hline Diabetes & & $29(9.67)$ & $19(6.33)$ \\
\hline Anemia & & $63(21)$ & $28(9.33)$ \\
\hline Hypertension & & $109(36.33)$ & $125(41.67)$ \\
\hline Infection & & $93(31)$ & $77(25.67)$ \\
\hline \multicolumn{4}{|l|}{ Socio-economic characteristics } \\
\hline Low & & $129(43)$ & $45(28.13)$ \\
\hline Average & & $125(41.67)$ & $65(40.63)$ \\
\hline High & & $46(15.33)$ & $50(31.25)$ \\
\hline
\end{tabular}

East J Med Volume:21, Number:1, January-March/2016 
Table 02 emphasizes the association between maternal sociodemographic characteristics and premature delivery for all the cases; the odds of mothers with an age less than 25 years were 5.8 (95\% CI 1.5-8.9). Other maternal variables such as primigravida $(\mathrm{OR}=7)$, primiparous $(\mathrm{OR}=6.23)$ and abortion $(\mathrm{OR}=2.1)$ were also significantly associated with premature delivery. Similarly maternal high blood pressure was significantly associated with premature delivery $(\mathrm{OR}=2.5)$.

'In the other hand, table 3 shows the frequency distribution of medical findings of premature delivered babies: the majority of them were premature $(89.67 \%)$ while only $4 \%$ were extremely premature. $2 / 3$ of premature babies were of low birth weight $(66.67 \%), 21 \%$ of intrauterine growth restriction and $32.67 \%$ were of neonatal death.

Analysis of significant risk factor for premature delivery $(p<0.001)$ shows that the odds of premature births were 3.02 times higher in twin delivery compared to single pregnancy (95\% CI 1.2, 4.26). Intra uterine growth was also marginally significantly associated with premature delivery $\mathrm{OR}=2.15$. The odds of icterus and asphyxia were respectively at 2.03 and 1.58 in premature babies. The association between fetal male and gender premature delivery was significant OR=1.3 (95\% CI.06-3.6).

\section{Discussion}

Maternal Socio-demographic characteristics: Maternal age of less than 20 years and more than 35 years are described as risk factors for premature delivery and perinatal mortality in many studies (11-
13). In our study, the maternal age of less than 25 years was found as risk factor for premature delivery with an odds ratio of 5.8 (95\% IC 1.5-8.9). Similar results were found in other studies (14). The association between parity and premature delivery is controversial. Some studies showed significant association between premature delivery and parity (15 -17). However, others showed contradicting findings between parity and premature delivery (18). In our study, primiparity and primigravida were significantly associated with premature delivery.

Few studies have associated primiparous as a risk factor for premature delivery (19-21). Nevertheless, this risk factor also depends on the age of mothers $(22,23)$.

Clinical Conditions underlying medically-indicated preterm birth can be divided into maternal and fetal of which severe preeclampsia, placental abruption, uterine rupture, cholestasis, fetal distress and fetal growth restriction with abnormal tests are some of the more important direct causes recognized (24). Underlying maternal conditions (e.g., renal disease, high blood pressure, obesity

Table 2. Association between maternal sociodemographic characteristics and premature delivery

\begin{tabular}{lccc}
\hline Factors & OR & $95 \%$ CI & $\mathrm{p}$ \\
\hline Age $<25$ years & 5.8 & $1.5-8.9$ & $<0.001$ \\
Primigestity & 7 & $3-16$ & $<0.001$ \\
Primiparity & 6.23 & $1.5-9.5$ & $<0.001$ \\
Abortion & 2.1 & $1.2-2.56$ & $<0.001$ \\
High blood presure & 2.5 & $2.5-5.66$ & $<0.001$ \\
\hline
\end{tabular}

Table 3. The frequency distribution of medical findings of premature delivered babies

\begin{tabular}{ccc}
\hline & $\mathrm{Nb}$ & $(\%)$ \\
\hline Prematurity rate & & 89.67 \\
1. Prematurity & 269 & 6.33 \\
$2 . \quad$ very premature & 19 & 4 \\
3. Extremely premature & 12 & 66.67 \\
\hline Weight & & 16.33 \\
1. LBW & 200 & 3 \\
2. Very LBW & 49 & 14 \\
3. Extremely LBW & 9 & 21 \\
$4 . \quad>2500 \mathrm{~g}$ & 42 & 26 \\
\hline Neonatal complication & 63 & 10 \\
LBW Anemia & 78 & 4 \\
Infection & 30 & 3 \\
Asphyxia & 12 & 24.67 \\
Meningitis & 9 & 32.67 \\
Icterus & 74 & 98 \\
\hline mortality & 98 & \\
\hline
\end{tabular}

East J Med Volume:21, Number:1, January-March/2016 
Table 4. Association between fetal characteristics and premature delivery

\begin{tabular}{lccc}
\hline Fetal characteristic & OR & CI 95\% & $\mathrm{p}$ \\
\hline Baby gender & & & \\
Male & 1.3 & $0.6-3.6$ & $<0.001$ \\
Female & 1 & & \\
\hline Twin & 3.02 & $1.2-4.26$ & $<0.001$ \\
triplet & 0.6 & & \\
\hline Asphyxia & 1.58 & $0.02-2.1$ & $<0.001$ \\
\hline Anemia & 0.69 & & \\
\hline LBW & 2.15 & $1.05-3.13$ & $<0.001$ \\
\hline Icterus & 2.03 & $1.05-3.13$ & $<0.001$ \\
\hline
\end{tabular}

and diabetes) increase the risk of maternal complications (e.g., preeclampsia) and medicallyindicated preterm birth. (25) In this study, the number of mothers with high blood pressure was associated with higher odds of premature births. $(\mathrm{OR}=2.5$.95\% IC 2.5-5.66). High blood pressure in pregnancy is believed to predispose to acute or chronic utero-placental insufficiency resulting in antepartum and intrapartum fetal hypoxia with associated adverse outcomes of which preterm delivery is one (26). Many studies described intrauterine infection as frequent and important mechanism leading to preterm birth $(27,28)$. In our study $31 \%$ of patient who's delivered prematurely suffered from genital infection.

Obstetrics history (Premature, abortion, Scarred uterus, low birth weight) were also found to be a risk factor for premature delivery in our study which are similar to other studies (24). Similarly, in their study Mercer et al. (29) reported that women with previous preterm deliveries had a 2.5fold increased risk in their next pregnancy.

Some lifestyle factors contribute as well to preterm birth include stress and excessive physical work, long times spent standing, nutritional status or smoking (30). Unfortunately, due to the retrospective nature of the study, the role of these factors in the prematurity were not able to be determined in our study.

Fetal characteristics: Twin pregnancy, Icterus and intra-uterine growth retardation are known as risk factors associated with premature delivery. It is due to the overstretching of the uterus which promotes preterm labour. Some studies showed association between of twin pregnancy with premature delivery $(16,31)$. In fact, births from multiple pregnancies are mostly premature. Twin pregnancy is a significant risk factor for premature delivery in this study with an adjusted odds ratio of 3.02 (95\% CI 1.2, 4.26). In
France, the rate of twin pregnancies was high with $86 \%$ as the main cause of prematurity (32).

The fetus itself could be the cause of premature delivery. If the growth was retarded or malformed, the fetus was prone to be born prematurely (33). Some studies showed significant association between intra-uterine growth babies and premature delivery $(33,34)$. In this study, intrauterine growth was a significant risk factor for premature delivery 2.15 (95\% CI 0.25 -3.14). Preterm birth rate was higher in males than in females which are similar to other studies who found that around $55 \%$ of all preterm births occurring in males (35), and that was associated with a higher risk of dying when compared to girls born at a similar gestation (36). However, the study McGil Ugwu (37) in Warri and Zeleke et al. (38) in Ethiopia reported more preterm females.

In the majority of the cases, pretem babies were hospitalized in neonatal intensive care units because of Icterus 2.03 (95\% CI 1.05-3.13), Asphyxia 1.58 (95\% CI 0.02-2.1), RCIU and LBW which were the most causes of preterm babies mortality (32.67\%). Similarly, Other African studies noted a mortality rate of $29 \%$ in Tanzania, (39) and $30.7 \%$ in Nigeria (40).

\section{Conclusion}

As causes of high morbidity and mortality, Prematurity is considered as major public health in developing countries. Even the inversions, which promote the affection of the mother to her newborn premature child, are appreciated and useful for the mothers, some amelioration should be added.

\section{References}

1. Goldenberg R, Culhane J, Iams J, Romero R. Epidemiology and causes of preterm birth. Lancet 2008; 371: 75-84.

2. Goldenberg R.L, Culhane JF, Iams JD, Romero R. Epidemiology and Causes of Preterm Birth. Lancet 2008; 371: 75-84.

3. Xu P, Zhang X, Li Y, Liu X, Qian SY. Health status and affecting factors of late-preterm infants 2009; 47 : 931-993.

4. Goldenberg RL, Hoffman HJ, Cliver SP. Neurodevelopmental outcome of small-forgestational-age infants. Eur J Clin Nutr 1998; 52(Suppl 1): 54-58.

5. Escobar GJ, McCormick MC, Zupancic JA, et al. Unstudied infants: Outcomes of moderately premature infants in the NICU. Arch Dis Child Fetal Neonatal Ed 2006; 91: F238-244. 
6. Goldenberg RL, Rouse DJ. Preterm birth, cerebral palsy and magnesium. Nat Med 1997; 3: 146-147.

7. Goldenberg RL, Rouse DJ. Prevention of premature birth. N Engl J Med 1998; 339: 313-320.

8. Slattery MM, Morrison JJ. Preterm delivery. Lancet 2002; 360: 1489-1497.

9. Gilbert WM, Nesbitt TS, Danielsen B. The cost of prematurity: Quantification by gestational age and birth weight. Obstet Gynecol 2003; 102: 488-492.

10. Petrou S. The economic consequences of preterm birth during the first 10 years of life. BJOG 2005; 112: 10-15.

11. Annual Report on Perinatal Mortality, Malaysia; 1998.

12. Ahern J, Pickett K, Selvin S, Abrams B. Preterm birth among African American and white women: a multilevel analysis of socioeconomic characteristic and cigarette smoking. J Epidemiol Comm Health 2002; 57: 606-611.

13. Naeye R, Peters E. Working during pregnancy: Effects on the fetus. Paediatrics 1982; 69: 724-727.

14. Lisonkova S, Janssen P, Sheps S, Lee S, Dahlgren L. The effect of maternal age on adverse birth outcomes: does parity matter? J Obstet Gynaecol Can 2010; 32: 541-548.

15. Meis P, Michioelutte R, Peters $T$, et al. Factors associated with preterm birth in Cardiff Wales. Am J Obstet Gynaecol 1995; 173: 590-596.

16. Martius J, Steck T, Oehler MK, Wulf K. Risk factors associated with preterm ( $<37$ weeks) and early preterm birth (<32 weeks): Univariate and multivariate analysis of 106345 singleton births from the 1994 statewide perinatal survey of Bavaria. European J Obstet Gynecol Reprod Biol 1998; 80: 183-189.

17. Cnattingius S, Forman MR, Berendes HW, Graubard BI, Isotalo L. Effect of age, parity, and smoking on pregnancy outcome: a population-based study. Am J Obstet Gynecol 1993; 168(1 Pt 1): 16-21.

18. Subtypes. J Matern Fetal Neonatal Med 2006; 19: 773-782.

19. Wessel H, Cnattingius S, Bergstrom S, Dupret A, Reitmaier P. Maternal risk factors for preterm birth and low birthweight in Cape Verde. Acta Obstet Gynecol Scand 1996; 75: 360-366.

20. Shah R, Bracken M. A systematic review and met analysis of prospective studies on the association between maternal cigarette smoking and preterm delivery. Am J Obstet Gynecol 2000; 182: 465-472.

21. Aragão VM, da Silva AA, de Aragão LF, et al. Risk factors for preterm births in São Luís, Maranhão, Brazil. Cad Saude Publica 2004; 20: 57-63.

22. Feresu S, Harlow S, Woelk Godfrey B. The risk factors for prematurity at Harare Maternity Hospital, Zimbabwe. Int J Epidemiol 2004; 33: 1194-1201.

23. Mamelle N, Laumon B, Lazar P. Prematurity and occupational activity during pregnancy. Am J Epidemiol 1984; 119: 309-322.
24. Ananth CV, Vintzileos AM. Epidemiology of preterm birth and its clinical subtypes. J Matern Fetal Neonatal Med 2006; 19: 773-782.

25. Steer P. The epidemiology of preterm labour. BJOG 2005; 112: 1-3.

26. Ferrer RL, Sibai BM, Mulrow CD, et al. Management of Mild Chronic Hypertension during Pregnancy: A Review. Obstetrics \& Gynecology 2000; 96: 849-860.

27. Knox IC Jr, Hoerner JK. The role of infection in premature rupture of the membranes. Am J Obstet Gynecol 1950; 59: 190-194.

28. Goldenberg RL, Hauth JC, Andrews WW. Intrauterine infection and preterm delivery. $\mathrm{N}$ Engl J Med 2000; 342: 1500-1507.

29. Mercer BM, Goldenberg RL, Moawad AH, et al. The preterm prediction study: eff ect of gestational age and cause of preterm birthon subsequent obstetric outcome. National Institute of Child Health and Human Development Maternal-Fetal Medicine Units Network. Am J Obstet Gynecol 1999; 181: 12161221.

30. Petrou S. The economic consequences of preterm birth.

31. Chen CP, Wang KG, Yang YC, See LC. Risk factors for preterm birth in an upper middle class Chinese population. Eur J Obstet Gynecol Reprod Biol 1996; 70: 53-59.

32. Vaksmann S, Bouchart P, Patey-Savatier P, et al. Multiple pregnancies: epidemiology, clinical aspects. J Gynecol Obstet Biol Reprod 1990; 19: 383-394.

33. Sorri ALH, Sorri MS. Occupational and socio-medical factors in preterm birth. Obstet Gynecol 1989; 74: 13-16.

34. Aro $\mathrm{T}$, Heinonen $\mathrm{O}$, Saxen L. Risk factors of reduction limb defects. J Epidemiol Comm Health 1983; 37: 50-56.

35. Zeitlin J, Saurel-Cubizolles MJ, De Mouzon J et al. Fetal sex and preterm birth: are males at greater risk? Hum Reprod 2002; 17: 2762-2768.

36. Kent AL, Wright IM, Abdel-Latif ME. Mortality and adverse neurologic outcomes are greater in preterm male infants. Pediatrics 2012; 129: 124-131.

37. McGil Ugwu GI. Prematurity in Central Hospital and GN Children's Clinic in Warri Niger Delta. Nigerian Medical Journal 2010; 51: 10-13.

38. Zeleke BM, Zelalem M, Mohammed N. Incidence and Correlates of Low Birth Weight at a Referral Hospital in North-West Ethiopia. The Pan African Medical Journal 2012; 12: 4.

39. Kidanto HL, Mogren I, Lindmark G, Massave S, Nystrom L. Risk for preterm delivery and low birth weight are independently increased by severity of maternal anaemia. S Afr Med J 2009; 99: 98-102.

40. Ezechukwu CC, Ugochukwu EF, Egbuonu I, Chukwuka JO. Risk factors for neonatal mortality in a regional tertiary hospital in Nigeria. Nig J Clin Pract 2004; 7: 50-52. 